\title{
MATHEMATICAL MODELLING AND EXPERIMENTAL STUDY OF STRAW CO-FIRING WITH GAS USING ELECTRIC FIELD CONTROL OF COMBUSTION CHARACTERISTICS
}

\author{
Harijs Kalis ${ }^{1}$, Antons Kolmickovs ${ }^{2}$, Maksims Marinaki ${ }^{1}$, Raimonds Valdmanis ${ }^{2}$ \\ ${ }^{1}$ Institute of Mathematics and Computer Science, University of Latvia, Latvia; \\ ${ }^{2}$ Institute of Physics, University of Latvia, Latvia \\ harijs.kalis@lanet.lv, antons.kolmickovs@lu.lv, maksims.marinaki@lu.lv, raimonds.valdmanis@lu.lv
}

\begin{abstract}
The main aim of the research is to provide wider and more efficient use of a renewable fuel - straw for energy production with reduced GHG carbon and polluting $\mathrm{NO}_{\mathrm{x}}$ emissions during co-firing straw pellets with gas (propane) und using the electric field control of thermochemical conversion of straw. A pilot plant with a combined biomass gasifier and combustion chamber with the heat power up to $4 \mathrm{~kW}$ has been used to provide the thermochemical conversion of straw pellets during co-firing with gas, which is supplied at the outlet of the gasifier with average heat input $0.8 \mathrm{~kW}$. A positively charged electrode was inserted axially into the flame base for electrical control of the thermal decomposition of straw pellets and combustion of volatile compounds (CO, $\mathrm{H}_{2}, \mathrm{C}_{\mathrm{x}} \mathrm{H}_{\mathrm{y}}$ ). The field-induced electric body force enhanced the mass transfer of combustible volatiles from the axial reaction zone toward the water-cooled walls of the combustor providing radial expansion of the reaction zone and enhancing the heat output from the device. The electric field effect on the combustion characteristics and heat output from the device was estimated from the results of the complex measurements of the flow velocity components, flame temperature of the produced heat energy per mass of burned volatiles and the composition of emissions by varying the bias voltage of the electrode in the range from 0 up to $2.4 \mathrm{kV}$ and the ion current in the range from 0 to $6 \mathrm{~mA}$. For the calculation and solving a system of 9 parabolic type PDEs for the 2D compressible laminar axisymmetric flow in a coaxial cylindrical pipe with the electric field between the axially inserted electrode and the grounded walls of the pipe and with the simple exothermic reaction the mathematical modelling is developed. The maximal values of the temperature, flow velocity components and the mass fraction of the products $\left(\mathrm{CO}_{2}\right)$ were estimated.
\end{abstract}

Keywords: co-firing, straw pellets, propane, electric field, gasification, combustion, mathematical model.

\section{Introduction}

With account to provide wider use of renewable fuels - agriculture residues (wheat straw pellets) for energy production with increased combustion efficiency and reduced GHG emissions in products, which allows mitigate the Earth climate changes and global warming [1], it is necessary to carry out effective control of the thermochemical conversion of straw pellets. The previous studies allow to conclude that effective control of the main combustion characteristics at thermochemical conversion of straw pellets can be achieved by co-firing with solid fuels or gases [2-4]. In addition, the electric field control of the main combustion characteristics (ion wind effects) can be used [5-9], when the field-induced electric body force enhances the radial mass transfer of combustible volatiles from the flame reaction zone outwards and the mixing of reactants with subsequent changes of the reaction rates, combustion efficiency, flame shape, structure, composition and the heat output from the device. As a result, the field-induced changes of produced heat energy and the composition of products are observed, which suggest that the field effects on the flame can be used for additional control of the processes developing at thermochemical conversion of straw pellets. For more effective electric control of straw pellet thermochemical conversion, during co-firing with gas, this study includes complex research by combining the experimental studies and mathematical modelling of combustion dynamics.

\section{Experimental studies}

Complex experimental studies of the electric field effects on the thermochemical conversion of wheat straw pellets were performed, which combine studies of the field effects on the thermal decomposition of straw pellets, the formation of combustible volatiles, their ignition, combustion, heat energy production and the formation of products at co-firing with gaseous fuel (propane). The experimental studies were provided using a pilot device COMB-1 (TRL-4 readiness level). The heat output of the device was $4 \mathrm{~kW}$ [9]. The main components of the experimental equipment are the biomass gasifier and the combustion chamber. A gas burner is inserted in the upper part of the gasifier above the pellet layer to provide additional heat to the unit up to $1 \mathrm{~kW}$, thus reaching $20 \%$ straw co- 
firing by heat. The average rate of the wheat straw thermal decomposition reaches $0.21 \mathrm{~g} \cdot \mathrm{s}^{-1}$ to $0.22 \mathrm{~g} \cdot \mathrm{s}^{-1}$ during combustion of volatiles (max-end), which corresponds to the total duration of the wheat straw $(450 \mathrm{~g})$ thermochemical conversion 2050-2100 s.

The thermal decomposition of straw pellets and the formation of combustible volatiles $\left(\mathrm{CO}, \mathrm{H}_{2}\right.$, $\mathrm{C}_{\mathrm{x}} \mathrm{H}_{\mathrm{y}}$ ) was supported, using the primary air supply below the layer of straw pellets at the average air excess ratio in the gasifier $\alpha \approx 0.5$. The ignition and combustion of volatile compounds was supported, using the secondary swirling air supply at the base of the combustion chamber with average rate $401 \cdot \mathrm{min}^{-1}$ determining the burnout of volatiles at average air excess ratio $\alpha \approx 1.22$.

To study the electric field effect on the thermochemical conversion of straw pellets during cofiring with gaseous fuel (propane), a nichrome electrode with a diameter of $3 \mathrm{~mm}$ and a length of $53 \mathrm{~mm}$ was used. The electrode was inserted axially at the base of the combustor upstream the flame flow and the positive bias voltage of the electrode was varied in the range from 0 up to $2.4 \mathrm{kV}$ and the ion current from 0 to $6 \mathrm{~mA}$.

Experimental studies of the straw pellet co-firing with gaseous fuel (propane) and the electrical control of these processes were carried out using the methods described in [8].

\section{Experimental results}

The influence of the electric field on the thermochemical conversion of straw pellets at co-firing with propane is significantly determined by the formation of the flame ions $\left(\mathrm{CHO}^{+}, \mathrm{H}_{3} \mathrm{O}^{+}, \mathrm{C}_{3} \mathrm{H}_{3}{ }^{+}\right)$ [6; 9], the average density of which approaches the peak value $\left(10^{17}-10^{18} \mathrm{~m}^{-3}\right)$ at the flame base. For given electrode configuration, the field enhances radial and upstream mass transfer of the neutral flame species, which disturbs the flow dynamics decreasing the local and average values of the axial flow velocity, which decreases from about $0.6 \mathrm{~m} \cdot \mathrm{s}^{-1}$ to about $0.3 \mathrm{~m} \cdot \mathrm{s}^{-1}$ (Fig. 1-a).

Besides, the field-enhanced reverse axial heat transfer up to the layer of straw pellets promotes enhanced heating and thermal decomposition of straw pellets, increasing the average weight loss rate of straw pellets from 0.22 to $0.24 \mathrm{~g} \cdot \mathrm{s}^{-1}$ by about $8 \%$ (Fig. 1-b), promoting the field-enhanced formation of combustible volatiles $\left(\mathrm{CO}, \mathrm{H}_{2}\right)$ and increasing the volume fraction of the volatiles at the flame base (Fig. 1-c), which are responsible for the changes of the combustion conditions at the inlet of the combustor, the average values of the flame temperature and the heat output from the device. It should be noticed that the competitive processes of the field-enhanced reverse axial and radial heat $\cdot \mathrm{m}^{-}$ ${ }^{1}$ ass transfer advance the complex variations of the flame temperature and heat output from the device determining decrease of the heat output from the device and flame temperature to the minimum value, which corresponds to ion current about $2 \mathrm{~mA}$ and when $I>2 \mathrm{~mA}$ starts to increase (Fig. 1-d).

At constant total air supply to the unit $\left(1.43 \mathrm{~g} \cdot \mathrm{s}^{-1}\right)$ determining the constant air excess ratio in the combustor $(\alpha \approx 1.22)$ during the thermochemical conversion of straw the field-enhanced formation of combustible volatiles improves the combustion conditions at the inlet of the combustor, decreasing the average value of the air excess ratio $(\alpha)$ from 1.22 to 1.14 (by about $7 \%$ ) and completing combustion of volatiles.

As a result, the produced heat energy per mass of burned straw pellets increases from $11.5 \mathrm{MJ} \cdot \mathrm{kg}^{-1}$ up to $12.8 \mathrm{MJ} \cdot \mathrm{kg}^{-1}$ (by about $11.4 \%$ ) (Fig. 1-e), increasing of $\mathrm{CO}_{2}$ the volume fraction in the products from $13.7 \%$ to $14.1 \%$ and combustion efficiency from $80 \%$ to $80.4 \%$ (Fig. 1-f), which confirms the field-enhanced improvement of the thermochemical conversion of straw pellets during co-firing with propane.

Therefore, the results of the experimental study suggest that the electric field-induced ion wind effects during co-firing straw pellets with propane can be used to provide additional control of straw thermochemical conversion advancing the local variations of the flow dynamics, thermal decomposition of biomass pellets, the formation and ignition of combustible volatiles and combustion conditions for the inlet flow. The field-enhanced improvement of the combustion conditions is responsible for complete combustion of volatile compounds increasing the combustion efficiency and produced heat energy per mass of burned straw. 

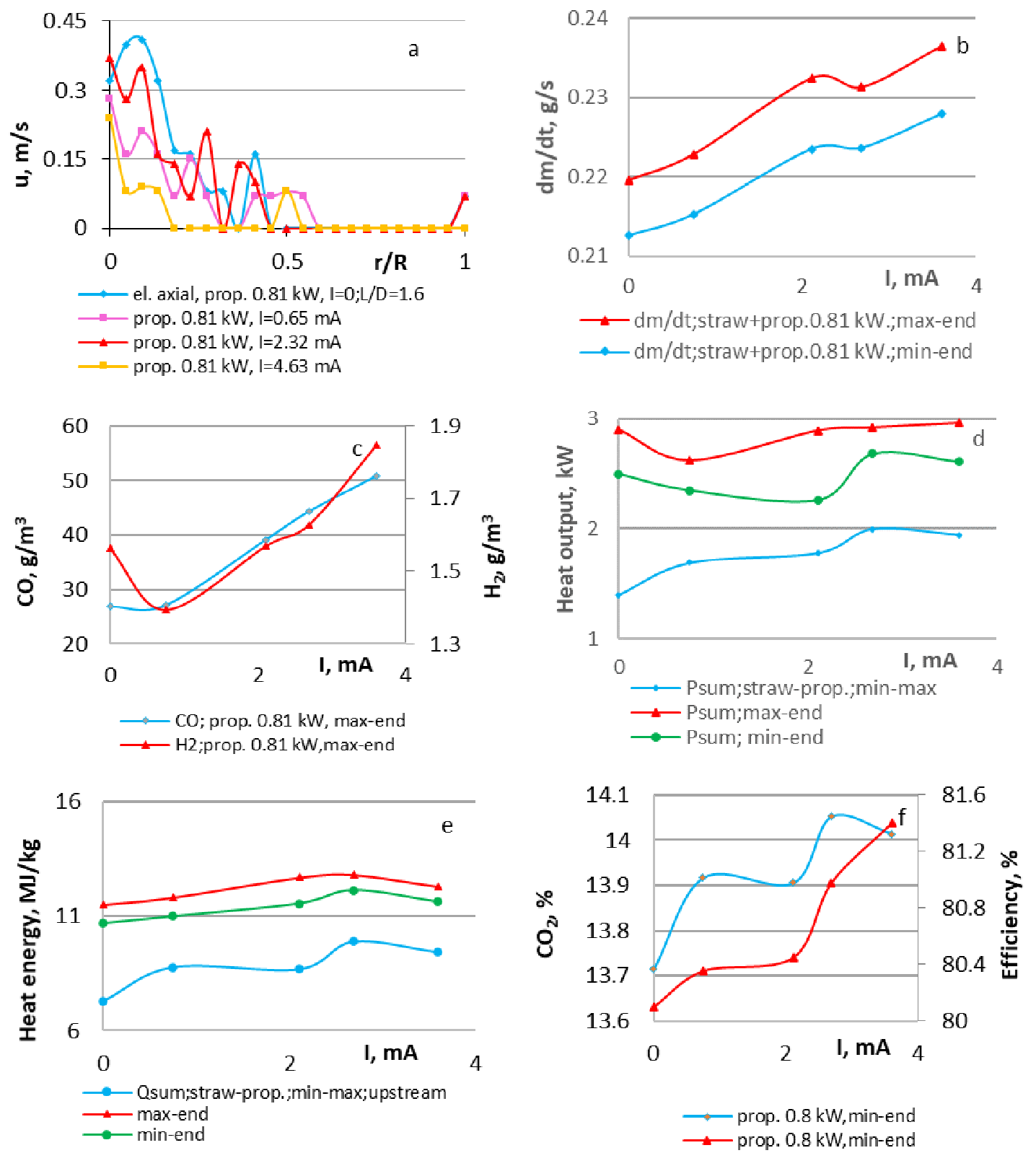

Fig. 1. Electric field effect on the axial flow velocity profiles (a), weight loss rate of straw pellets (b), the volume fraction of combustible volatiles at the inlet of the combustor (c), the heat output from the device and average value of the flame temperature $(d)$, produced heat energy per mass of burned mixture (e), the volume fraction of $\mathrm{CO}_{2}$ in the products and the combustion efficiency (f)

\section{Mathematical model}

The previously developed mathematical model [14] considers the effect of additional heat supply by gaseous fuel (propane flame) on the process developing during thermochemical conversion of straw pellets downstream the cylindrical pipe (combustor). The results of mathematical modelling suggest that additional heat supply by propane flame flow during co-firing straw pellets makes it possible to control the processes developing at thermochemical conversion of straw, as it follows from the results of experimental studies. By improving the mathematical model [14], the possibilities to perform additional control of the processes developing during straw co-firing with gas were evaluated [13], considering the electrodynamic effects of the electric Lorentz force on the flame flow. The previously developed mathematical model, which evaluates the electric field effects on straw thermochemical conversion during co-firing with gas (propane) [13] used MATLAB for solving a 
system of parabolic type partial differential equations to describe the formation of the 2D compressible reacting swirling flow in coaxial cylindrical pipe with account of the variation of the mass fraction of volatiles, the flame species and the flame temperature. A simplified model of this study is developed for compressible, low speed $\left(0.1 \mathrm{~m} \cdot \mathrm{s}^{-1}\right)$ laminar, axisymmetric flame flow with estimation of the effect of developing exothermic reactions during the burnout of propane on combustion of volatiles. Analogous to the electric field configuration used in the experimental studies, the electric field was applied in the space between the axially inserted electrode and the grounded walls of the combustor.

A numerical simulation of a $2 \mathrm{D}$ axially symmetric flow (velocities $u_{r}, u_{z}, u_{\varphi}$ ) with density $\rho$ was carried out, when the combustion of volatiles develops downstream the cylindrical pipe (combustor) with the radius $r_{0}=0.05 \mathrm{~m}$ and length $z=z_{0}=0.1 \mathrm{~m}$. The primary air, the axial flow of volatiles and the reactants of propane and oxygen entering the combustor, were supplied at $r \in\left[0, r_{1}\right]\left(r_{1}=0.033 \mathrm{~m}\right)$ with the axial velocity $U_{0}=0.1 \mathrm{~m} \cdot \mathrm{s}^{-1}$, density $\rho_{0}=1 \mathrm{~kg} \cdot \mathrm{m}^{-3}$; the inlet temperature was $T_{0}=300 \mathrm{~K}$. The secondary swirling air was supplied at $r \in\left[r_{1}, r_{0}\right]$ with the azimuthal velocity $V_{0}>U_{0}$ (the swirl number $\left.S=V_{0} / U_{0}=3\right)$.

The mathematical model is described by the four Euler (values $\rho, u_{z}, u_{r}, r u_{\varphi}$ ), the temperature $(T)$, four reaction-diffusion (mass fractions $\mathrm{C}_{1}=\mathrm{C}_{3} \mathrm{H}_{8}, \mathrm{C}_{2}=\mathrm{O}_{2}, \mathrm{C}_{3}=\mathrm{CO}_{2}, \mathrm{C}_{4}=\mathrm{H}_{2} \mathrm{O}$ ) and azimuthally induced magnetic field (component $B_{\varphi}$ ) dimensionless equations in the cylindrical coordinates $(r, z)$ at time $t[10 ; 11 ; 14]$, the exothermic reaction $\mathrm{C}_{3} \mathrm{H}_{8}+5 \mathrm{O}_{2} \rightarrow 3 \mathrm{CO}_{2}+4 \mathrm{H}_{2} \mathrm{O}$, with the molecular weights $m_{k}\left(\mathrm{~g} \cdot \mathrm{m}^{-3}\right)$ and the specific enthalpy $h_{k}, \mathrm{~kJ} \cdot \mathrm{mol}^{-1}$ of the species $C_{k}\left(m_{1}=44, m_{2}=32, m_{3}=44, m_{4}=18\right.$, $\left.h_{1}=-105, h_{2}=0, h_{3}=-394, h_{4}=-242\right), k=1(1) 4, \delta=18.75$ is the scaled activation energy, $\lambda=0.25, \mathrm{~J} \cdot(\mathrm{s} \cdot \mathrm{m} \cdot \mathrm{K})^{-1}$ is the thermal conductivity, $D=2.5 \cdot 10^{-4} \mathrm{~m}^{2} \cdot \mathrm{s}^{-1}$ is the molecular diffusivity of the species, $c_{p}=1000, \mathrm{~J} \cdot(\mathrm{kg} \cdot \mathrm{K})^{-1}$ is the specific heat at a constant pressure, $q=\left(m_{1} h_{1}-3 m_{3} h_{3}-4\right.$ $\left.m_{4} h_{4}\right) /\left(c_{p} \cdot T_{0} \cdot m_{1} \cdot m\right)$ is the scaled heat release, $\left(m\right.$ - averaged molecular weight) $A_{1}=A^{\prime}{ }_{1} \cdot r_{0} \rho_{0}{ }^{5} /\left(U_{0} \cdot m_{2}{ }^{5}\right)$ is the scaled pre-exponential factor, $A^{\prime}{ }_{1}=14 \mathrm{~m}_{1}{ }^{5} \cdot\left(\mathrm{mol}^{5} \mathrm{~s}\right)^{-1}$ [12].

The values of $\operatorname{Re}=10000$ are used for the factors of the artificial viscosity for approximation of the velocity equations. The equations were made dimensionless by scaling all the lengths to $r_{0}\left(x=z / r_{0}\right)$, the meridian velocity to $U_{0}$, the azimuthal velocity $v_{\varphi}$ to $V_{0}=0.3, \mathrm{~m} \cdot \mathrm{s}^{-1}$, the temperature to $T_{0}$, the pressure to $\rho_{0} \cdot U_{0}^{2} \mathrm{~N} \cdot \mathrm{m}^{-2}$, the current density (between the walls of the combustor and the electrode at the combustor inlet) $[10,11]$ to $j_{0}=I /\left(2 \cdot \pi \cdot r_{0}{ }^{2}\right), \mathrm{A} \cdot \mathrm{m}^{-2}$, the azimuthal component of the magnetic field to $B_{0}=\mu \cdot I /\left(2 \cdot \pi \cdot r_{0}\right)$, T, the radial and axial components of the electromagnetic forces to $F_{0}=j_{0} \cdot B_{0},\left(\mathrm{~N} \cdot \mathrm{m}^{-3}\right)$, where $\mu=4 \pi \cdot 10^{-7}, \mathrm{~N} \cdot \mathrm{A}^{-2}$ is the magnetic permeability, $I=0.5-2, \mathrm{~mA}$ is the electric current. The dimensionless electromagnetic forces were quantified using the parameter $P_{e}=B_{0} \cdot j_{0} \cdot r_{0} /\left(\rho_{0} \cdot U_{0}^{2}\right)$. For the dimensionless pressure $p$ a model for perfect gas is used: $p=\rho T$.

The boundary conditions are in $[10 ; 11]$. For chemical reaction the boundary conditions of $\mathrm{C}_{1}, \mathrm{C}_{2}$ at the combustor inlet $x=0\left(C_{1}=C_{10} ; C_{2}=C_{20}, C_{10}+C_{20}=1\right)$ follows that for $C_{10} / C_{20}: m_{1} /\left(5 m_{2}\right)=44 /$ $/(5 \cdot 32)=11 / 40$, or $C_{10}=0.22, C_{20}=0.78[14]$.

For inviscid laminar flow (big Re number) we have PDE of hyperbolic type. In this case for convective terms we use the implicit FDS in time and the upwind differences in space [7]. The second order derivatives are approximated with central differences. For solving the discrete problem, we use the ADI method of Douglas and Rachford [15] in the vector form of 10 elements from unknown values. For the stationary solution with the maximal error $10^{-7}$, approximately 10000 -time steps were used.

\section{Results and discussion of mathematical modeling}

The distribution of the axial, radial and azimuthal components of velocity, density and temperature was calculated with MATLAB (Table 1).

From numerical simulations (Table 1) it follows that the maximum dimensionless values of the mass fraction of the products $\left(C_{3 \max }, C_{4 \max }\right)$, the temperature $\left(T_{\max }\right)$, the axial velocity $\left(w_{\max }\right)$, the radial velocity $\left(u_{\max }\right)$ and the negative values for $u\left(u_{\min }\right)$ increase at $P_{e}>0$, but the minimum values of the mass fraction of the reactants $\left(C_{1 \min }, C_{2 \min }\right)$ decrease. For the physical experiment in Fig. 1-e, $\mathrm{f}$ we can see the corresponding increase of the heat energy and volume fraction of $\mathrm{CO}_{2}$ when electric current is increased. 
Table 1

Dimensionless maximum and minimum values of the mass fractions, velocities and temperature variations depending on the electromagnetic parameter $\boldsymbol{P}_{e}$

\begin{tabular}{|c|c|c|c|c|c|c|c|c|}
\hline $\boldsymbol{P}_{\boldsymbol{e}}$ & $\boldsymbol{C}_{\mathbf{3 m a x}_{\max }}$ & $\boldsymbol{C}_{\text {4max }}$ & $\boldsymbol{w}_{\max }$ & $\boldsymbol{u}_{\max }$ & $\boldsymbol{u}_{\min }$ & $\boldsymbol{T}_{\max }$ & $\boldsymbol{C}_{\mathbf{1} \min }$ & $\boldsymbol{C}_{\mathbf{2 m i n}}$ \\
\hline 0 & 0.390 & 0.213 & 2.58 & 2,54 & 0 & 1.45 & 0.090 & 0.308 \\
\hline 0.5 & 0.530 & 0.289 & 3.36 & 2.66 & -1.03 & 1.75 & 0.043 & 0.137 \\
\hline 1.0 & 0.587 & 0.320 & 4.32 & 2.71 & -2.19 & 2.05 & 0.024 & 0.068 \\
\hline 2.0 & 0.634 & 0.346 & 6.81 & 2.78 & -3.78 & 2.33 & 0.009 & 0.011 \\
\hline
\end{tabular}

The increase of the temperature and mass fraction of the products by increasing the magnetic field-induced Lorentz force (parameter $P_{e}$ ) is visible in Figs 2,3. The maximum value of the temperature is obtained in the flame reaction zone $\left(r / r_{0}<0.45\right)$, the profiles are monotonically decreasing in $\mathrm{r}$ (Figs. 2, a, b), but by $\mathrm{P}_{\mathrm{e}}=2$ the flame is deleted outside this zone for $x<0.5$ (Fig. 2,b). Similar behavior we can see in Fig. 3 for $\mathrm{CO}_{2}$ mass fraction at $r / r_{0}<0.25$.
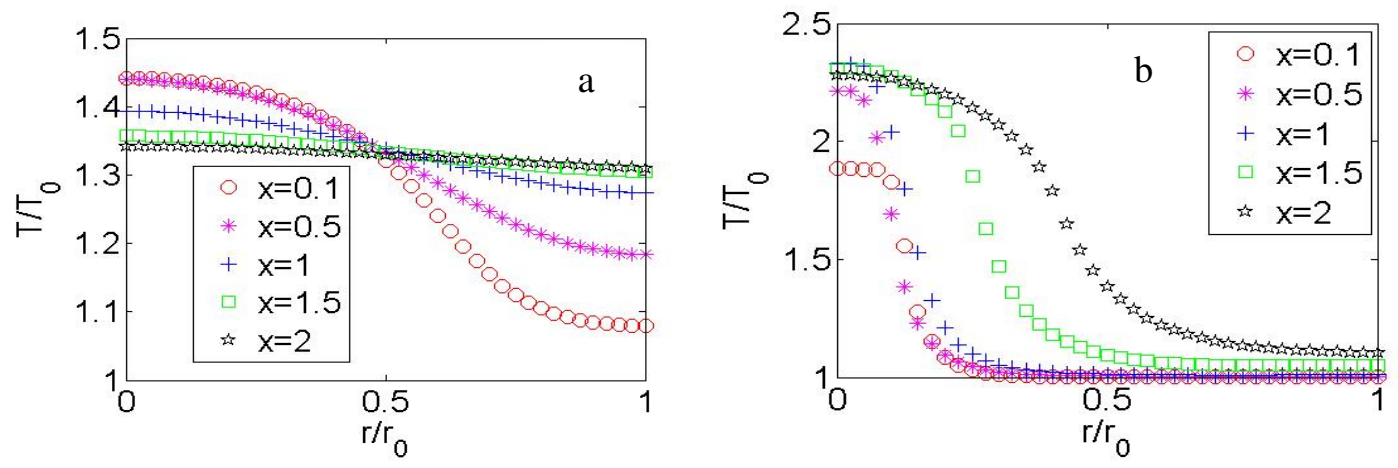

Fig. 2. Electric field-induced variations of the radial distribution of the flame temperature: a) $P_{e}=0, \mathrm{MT}=1.45$, (b) $P_{e}=2, \mathrm{MT}=2.33$.
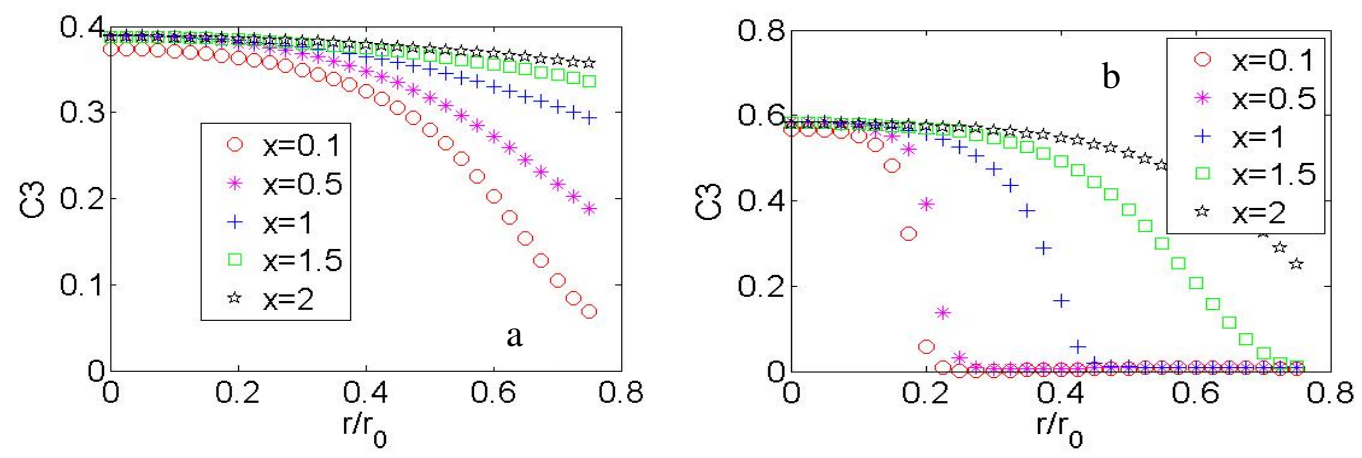

Fig. 3. Electric field effect on the radial profiles of the mass fraction of the products $\left(\mathrm{CO}_{2}\right)$ : (a) $P_{e}=0, \operatorname{Max}=0.390$, (b) $P_{e}=1, \operatorname{Max}=0.587$.

\section{Conclusions}

Considering the results of the experimental studies carried out in this work, leads to the conclusions:

1. To provide wider use of renewable fuel - straw for clean and efficient energy production, the electric field effects on the swirling flame flow can be used to provide control of the flow dynamics, the thermal decomposition of straw pellets, produced heat energy per mass of burned straw pellets and the formation of combustible volatiles improving the combustion conditions, the main flame characteristics and the product composition during co-firing of straw pellets with gaseous fuel (propane). 
2. The results of the numerical simulation confirmed that the formation of the flame reaction zone is modified by the electric field-induced variations of the flow velocity, temperature and by the mixing of the reactants, when increasing the electric current up to $I<0.005 \mathrm{~A}\left(P_{e}<2\right)$.

\section{Acknowledgements}

The authors would like to express their gratitude for financial support from the European Regional Funding for Project SAM 1.1.1.1/16/A/004.

\section{References}

[1] 2030 climate \& energy framework, Climate Action. [online] [02.01.2019]. Available at: https://ec.europa.eu/clima/policies. $\mathrm{s}^{-1}$ trategies/2030_en

[2] Barmina I., Valdmanis R., Zake M. The effects of biomass co-gasification and co-firing on the development of combustion dynamics. Energy, vol. 146, 2018, pp. 4-12. DOI: 10.1016/j.energy.2017.04.140

[3] Barmina I., Kolmickovs A., Valdmanis R., Zake M., Kalis H., Strautins U. Experimental study and mathematical modelling of straw co-firing with peat. Chemical Engineering Transactions, vol. 65, 2018, pp. 91-96. DOI:10.3303/CET1865016. [online][11.02.2020] Available at: http://www.aidic.it/cet/18/65/016.pdf

[4] Agbor E.U. Biomass co-firing with coal and natural gas. Thesis Master of Science, University of Alberts, Department of Mechanical Engineering, Canada 2015, 119 p. DOI: 10.7939/R3DJ58T7F, [online][11.02.2020] Available at: https://era.library.ualberta.ca/items/8a0929a3-1cdd-4caf-b058c2195f5a4c1e

[5] Lawton J., Weinberg F. Electric Aspects of Combustion. Oxford, UK: Clarendon Press, 1969, $650 \mathrm{p}$.

[6] Blades A.T. Ion formation in hydrocarbon flames. Can. J. Chem. 1976, 54, pp. 2919-2924.

[7] Colannino J. Electrodynamic Combustion Control Technology. A Clear Sign White Paper, Clear Sign Combustion Corporation, Seattle, 2012. [online][11.02.2020] Available at: https://www.clearsign.com/wp-content/uploads/2012/07/ClearSign-Whitepaper-2012-06-18.pdf.

[8] Barmina I., Purmalis M., Valdmanis R., Zaķe M., 2016, Electrodynamic control of the combustion characteristics and heat energy production, Combustion science and technology, vol. 188 (2), pp. 190-206. DOI: 10.1080/00102202.2015.1088010

[9] Barmina I., Kolmickovs A., Valdmanis R., Vostrikovs S., Electrodynamic control of straw cofiring with propane, Proceedings of 18th International Scientific Conference "Engineering for Rural Development”, Jelgava, 2019, pp. 1319-1324.

[10] Kalis H., Marinaki M., Strautins U., Zake M. On numerical Simulation of Electromagnetic Field Effects in the Combustion Process, Mathematical Modelling and Analysis, vol. 23, issue 2, 2018, pp. 327-343. 04.2018. DOI: 10.3846 $\mathrm{m}^{-1} \mathrm{ma} .2018 .020$. [online][11.02.2020] Available at: https://journals.vgtu.lt/index.php. $\mathrm{m}^{-1} \mathrm{MA} /$ article/view/1434/1143

[11] Kalis H., Marinaki M., Strautins U., Barmina I. Influence of electric field on thermo- chemical conversion of mixtures of straw pellets with coal. Proc. of int. conf. "Engineering for rural development", Jelgava, 23.-25.05.2018., pp. 1746-1753, DOI: 10.22616/ERDev2018.17.N299.

[12] Martinez I. Combustion kinetics set of lectures. p. 47, 2014, [online][11.02.2020] Available at: http://webserver.dmt.upm.es/ isidoro/bk3/c15/Combustion.pdf.

[13] Kalis H., Marinaki M., Ozola L., Strautins U. Numerical study of electrodynamic control of straw co-firing with propane. Proc. of int. conf. "Engineering for Rural Development", Jelgava, 22.24.05.2019, pp. 1198-1204, DOI: 10.22616/ERDev2019.18N330.

[14] Kalis H., Marinaki M., Strautins U., Ozola L., Barmina I., Kolmickovs A., Valdmanis R., Zaķe M., Mathematical modelling and experimental study of co-firing straw with gas. Mathematical Modelling and Analysis, 2019, vol. 24, Issue 4, pp. 507-529, DOI: $10.3846 \cdot \mathrm{m}^{-1} \mathrm{ma} .2019 .031$

[15] Douglas J., Rachford R. On the numerical solution of heat conduction problems in two and three space variables. Trans. Amer. Math. Soc., vol. 82(2),1956, pp. 421-439. 